\title{
Maternidade e Escolarização: Reflexões Sobre os Direitos Sexuais e Reprodutivos em uma Instituição Escolar Pública
}

\section{Maternity and Schooling: Reflections on Sexual and Reproductive Rights in a Public School}

\author{
Stellamary Brandão Rodrigues Gaia ; Jaileila de Araújo Menezes ${ }^{\mathrm{b}}$; Roseane Amorim da Silva ${ }^{\mathrm{c}^{*}}$ \\ ${ }^{a}$ Instituto Capibaribe. PE, Brasil. \\ bUniversidade Federal de Pernambuco, Programa de Pós-Graduação Stricto Sensu em Psicologia. PE, Brasil. \\ 'Universidade Federal Rural de Pernambuco, Centro de Filosofia e Ciências Humanas. PE, Brasil. \\ *E-mail: roseaneamorims@gmail.com
}

\begin{abstract}
Resumo
Este trabalho buscou compreender os significados produzidos sobre o evento maternidade na adolescência em contexto de escolarização, considerando o campo dos direitos sexuais e reprodutivos. A pesquisa é de caráter qualitativo, e para o desenvolvimento da mesma foi realizada entrevista com uma adolescente mãe e três profissionais de educação de uma escola pública de Recife/PE. Os dados construídos foram analisados a partir da análise temática, e foram apreendidas três categorias temáticas: significados produzidos sobre o evento maternidade na adolescência; o posicionamento dos sujeitos acerca do campo dos direitos reprodutivos; e estratégias utilizadas pelos/as atores e atrizes do contexto escolar e pela adolescente para garantia do seu processo de escolarização. Destacam-se as dificuldades vivenciadas pela estudante para dar continuidade ao processo de escolarização concomitantemente à experiência da maternidade. Identificam-se as lacunas existentes na Instituição Escolar quando se investiga sobre os direitos sexuais e reprodutivos para uma aluna adolescente mãe, no que se referem aos conhecimentos apresentados pelos profissionais de Educação sobre esse assunto e no modo de prestar assistência domiciliar a estudante mãe em período de licença maternidade. Considera-se importante que esses direitos sejam garantidos na Instituição Escolar, a fim de contribuir para a autonomia das adolescentes nas vivências ligadas à sexualidade e para a permanência das mesmas em processo de escolarização.
\end{abstract}

Palavras-chave: Adolescência. Maternidade. Escolarização.

\begin{abstract}
This work aimed to understand the meanings produced on the maternity event in adolescence in the context of schooling, considering the field of sexual and reproductive rights. The research is qualitative, and for the development of the same an interview was conducted with an adolescent mother and three education professionals from a public school in Recife/PE. The constructed data were analyzed from the thematic analysis, and three thematic categories were comprised: Significance produced on the maternity event in adolescence; The subjects 'positioning about the field of reproductive rights; and Strategies used by the actors and actresses of the school context and the adolescent to guarantee their schooling process. It is highlighted herein the difficulties experienced by the student to continue the schooling process concomitantly with the motherhood experience. Thegaps were identified in the school institution when the sexual and reproductive rights of a female adolescent mother were investigated, regarding the knowledge presented by education professionals about this subject and the way of providing home care to the mother student on maternity leave. It is considered important that these rights be guaranteed in the school institution, in order to contribute to the adolescents' autonomy in the experiences related to sexuality and to the permanence of the same in the schooling process.
\end{abstract}

Keywords: Adolescence. Maternity. Schooling.

\section{Introdução}

As discussões sobre adolescência, muitas vezes, apresentam uma perspectiva desenvolvimentista e tutelar, em que essa fase da vida é entendida como um processo de transição entre a infância e a vida adulta, caracterizada pelos impulsos considerados como típicos do desenvolvimento físico, mental, emocional, sexual e social. As marcações de início e término desse período denotam bem a complexidade da adolescência, desde os aspectos biológicos das mudanças corporais da puberdade, a dimensão psicológica - relativa à elaboração do luto da infância e construção de identificações fundamentais à construção de projetos de vida -, e as marcações cronológicas, que delimitam a inclusão/exclusão em medidas protetivas entre os 12 e 18 anos, conforme prescreve o Estatuto da Criança e do Adolescente - ECA.
Idealmente se espera que todas essas vivências (biológicas, psicológicas, cidadãs) ocorram em meio ao processo de escolarização na Educação Básica (MORAES; VITALLE, 2012; ROHR; SCHWENGBER, 2013; BRABO; SILVA; MACIEL, 2020).

A capacidade da autonomia dos/das adolescentes vem sendo alvo de muitas críticas nos estudos desenvolvimentistas, principalmente, no que se refere às interpretações realizadas ao exercício da sexualidade. Nesse sentido, dificilmente se percebem atividades específicas com o tema sexualidade nas escolas, sendo a temática da "Orientação Sexual” indicada para inserção no currículo escolar através dos Temas Transversais dos Parâmetros Curriculares Nacionais (BRASIL, 1997). $\mathrm{O}$ contexto escolar, quando realiza ação pedagógica sobre sexualidade, privilegia o combate a gravidez na adolescência 
e a proteção contra as doenças sexualmente transmissíveis em conformidade com o paradigma de uma escola normativa, que padroniza comportamentos, condutas e pensamentos.

Rohr e Schwengber (2013), em sua pesquisa com adolescentes em processo de escolarização, ratificam que as Instituições Escolares não possuem projetos que trabalhem questões sobre a sexualidade e a gravidez na adolescência, e quando o fazem, são ações isoladas em disciplinas (comumente de Ciências e de Biologia) e por iniciativa do docente. Para essas autoras, as escolas não estão preparadas para atender as novas demandas da sociedade, pois ainda entendem as vivências sexuais dos/das adolescentes pela lógica exclusiva do risco/perigo/agravo. Particularmente sobre os significados da gravidez, opera-se com o significante do retrocesso na vida dos/as adolescentes, sem considerar outras produções semióticas para este evento, a partir da realidade social. Em uma dimensão contra hegemônica, pesquisas que escutam os/as adolescentes sobre o evento gravidez têm visibilizado conexões positivas entre a maternidade/paternidade e um maior empenho em concretizar projetos de vida, a progressão da infância para a fase adulta e a possibilidade de reconhecimento social, bem como a idealização de um futuro melhor por intermédio de um filho.

Diante da diversidade de sentidos da vivência de uma gravidez na adolescência se considera ser de fundamental importância a garantia da permanência de adolescentes em processo de escolarização. Segundo Carvalho e Matsumoto (2009), na maioria das vezes, a interrupção precoce dos estudos ocorre em maior número em adolescentes de menor renda familiar, promovendo restrições em seus projetos de vida e menores oportunidades de inserção no mercado de trabalho.

A partir deste cenário, quais seriam as interpretações e aplicações da legislação para as adolescentes mães, a fim de que seja garantido o direito à educação, concomitantemente com a licença maternidade, uma vez que esta estaria regulamentada na Lei Federal $n^{\circ} 6.202 / 75$ ? Tal Lei garante para a gestante a possibilidade de continuar os estudos em regime domiciliar após o oitavo mês da gestação. No entanto, será que esta Lei vem sendo cumprida nas Instituições de Ensino? Entende-se que o cumprimento da Lei Federal $n^{\circ}$ 6.202/75, em articulação com o campo dos direitos reprodutivos, é de extrema importância para milhares de adolescentes que engravidam no período em que ainda estão em processo de escolarização.

Quando acima é feita referência à articulação da Lei com os Direitos Reprodutivos, é relevante abordar também a importância da garantia dos Direitos Sexuais e Reprodutivos, que são direitos de extrema importância para a ampliação dos direitos humanos, pois a vivência plena e consciente das sexualidades proporciona uma vida mais digna, no que diz respeito à individualidade e também à coletividade (BRABO; SILVA; MACIEL, 2020). Nesse sentido, este estudo buscou compreender os significados produzidos em uma Instituição de Educação Básica sobre o evento da gravidez/maternidade na adolescência e os desafios enfrentados para garantir os direitos e, consequentemente, a permanência da estudante em processo de escolarização.

\section{Material e Métodos}

Este estudo é de cunho qualitativo, pois se preocupa com o universo de significados, motivos, aspirações, crenças, valores e atitudes, o que corresponde a um espaço mais profundo das relações, dos processos e dos fenômenos que não podem ser reduzidos à operacionalização de variáveis (MINAYO, 1994). A pesquisa foi aprovada pelo Comitê de Ética em Pesquisa da Universidade Federal de Pernambuco - UFPE. Número do parecer pelo CEP- 0346.0.172.000-11. A coleta de dados aconteceu no segundo semestre de 2015.

Participaram desta pesquisa: uma adolescente mãe em período de escolarização e três profissionais de Educação, que desenvolvem atividades na Instituição Escolar em que a adolescente estuda e foram por ela indicados - o gestor, a coordenadora e um professor. A Instituição Escolar está localizada na Região Metropolitana do Recife, sendo uma escola pública do Governo do Estado de Pernambuco. Para a construção dos dados foram realizadas entrevistas semiestruturadas, pois este tipo de entrevista combina perguntas abertas e fechadas, em que o/a entrevistador/a tem a possibilidade de discorrer sobre o tema em questão sem se prender à pergunta formulada (MINAYO, 2009). Todas as entrevistas foram em áudio, sendo gravadas e transcritas na íntegra. Todos/as participantes assinaram o Termo de Consentimento Livre e Esclarecido, com as devidas informações sobre os objetivos e garantia de anonimato ao representante legal da adolescente e aos outros sujeitos envolvidos na pesquisa, bem como o anonimato da adolescente que assinou o Termo de Assentimento Livre e Esclarecido TALE.

Para análise dos dados foi realizada a análise temática, que busca "descobrir os núcleos de sentindo que compõem uma comunicação, cuja presença ou frequência signifiquem alguma coisa para o objetivo analítico visado" (MINAYO, 2009, p.209). Nesses termos, elencam-se três categorias temáticas: 1) Significados produzidos sobre o evento maternidade na adolescência; 2) O posicionamento dos sujeitos acerca do campo dos direitos reprodutivos; 3) Estratégias utilizadas pelos/as atores do contexto escolar e pela adolescente para garantia do seu processo de escolarização. Visando preservar a identidade dos/das participantes se faz referência a eles/ elas a partir de nomes fictícios: Cristiano (gestor), Jéssica (coordenadora), Heleno (professor) e Sophia (aluna).

Todos/as os profissionais participantes do presente estudo possuem Ensino Superior completo. O gestor tem 53 anos de idade, é solteiro, católico, atua na escola há quase vinte e cinco anos e tem renda familiar entre cinco e sete salários mínimos. A coordenadora tem 53 anos de idade, é viúva e 
católica, trabalha como coordenadora há quinze anos e tem renda familiar entre cinco e sete salários mínimos. O professor efetivo na Instituição Escolar leciona as disciplinas de Física e Matemática, tem 47 anos de idade, é casado, considera-se espiritualista e trabalha há dez anos, tendo renda familiar de um a três salários mínimos. A aluna adolescente mãe tem 16 anos, cursa a $4^{\mathrm{a}}$ Fase/ EJA, estava namorando (à época da coleta de dados) e mora com os pais, irmãos e a filha. É católica e a renda mensal familiar é de dois a quatro salários mínimos. Todos esses dados são relativos ao período em que a pesquisa foi realizada.

\section{Resultados e Discussão}

\subsection{Perdas e ganhos: ambivalências da maternidade na adolescência}

Considerando a gravidez como um evento que traz para a vida da mulher mudanças permanentes e significativas (corporais, sociais, psíquicas), este estudo buscou compreender os significados produzidos por participantes do contexto escolar acerca do evento maternidade na adolescência.

Para a aluna adolescente mãe, a maternidade não foi algo desejado e nem planejado. A estudante afirma não ter maturidade suficiente para ser responsável por uma criança, como se pode observar no relato abaixo:

$\mathrm{Eu}$ não queria porque eu não tenho cabeça pra ser mãe entendeu? Eu já fiquei pensando, eu me acordava de dez horas da manhã, hoje me acordo de quatro em quatro horas, não consigo nem dormir, não foi planejada não. [...] eu fiquei assustada né! Porque eu sou uma criança cuidando de outra. Eu não sabia nem pegar nela quando ela nasceu (Sophia, 16 anos).

A estudante enfatiza a falta de desejo e de preparo para a experiência da maternidade, a gravidez não foi planejada, ou seja, enquanto adolescente foi privada de seus direitos sexuais e reprodutivos, o que está bem representado pelo uso do verbete assustada. Em seu sentido dicionarizado, assustada é a condição de quem vivencia um susto, substantivo masculino que se refere a uma circunstância ameaçadora ou imprevista, podendo também indicar um abalo emocional provocado por notícias ruins e inesperadas. A privação do direito de planejar uma gravidez na adolescência tem direta relação com o próprio uso do termo e das práticas educativas e de saúde em torno do planejamento familiar. O termo é revestido de moralismo e perpassado por uma perspectiva adultocêntrica e excludente de sexualidade. No campo dos direitos há que se garantir o planejamento reprodutivo, entendendo a reprodução como algo que se coloca nas vidas das pessoas na condição de um projeto que antecede a fase adulta e extrapola a instituição do matrimônio/casamento.

Em nosso país, comumente as instituições (família, escola, igreja) atuam no campo da culpabilização da adolescente pela gravidez e não levam em consideração também a responsabilização do Estado pela ausência de políticas efetivas que garantam atenção, orientação, cuidado e educação, dimensões fundamentais para a construção de autonomia e emancipação nas escolhas sexuais e reprodutivas. A ausência do apoio da família e da escola contribui muito para o abandono escolar após a gestação, muitas vezes justificado pela necessidade de trabalhar e de também cuidar do bebê, sobretudo, nas famílias de baixa renda. Nas famílias de classe média, é comum no começo os pais não aceitarem e mostrarem insatisfação, mas depois apoiam as filhas para que essas consigam construir um projeto de vida (RODRIGUES; SILVA; GOMES, 2019).

No estudo realizado por Stein (2018) foi visto, também, que a experiência da maternidade se apresenta para algumas adolescentes como "solitária", porque implicou no afastamento de circuitos de lazer comuns nesse período da vida e delimitou as atividades de rotina delas aos afazeres domésticos, em torno da maternidade. O que mais uma vez mostra a importância da rede de apoio na vida de uma adolescente que se torna mãe. No referido estudo também é abordado que, às vezes, o pai da criança abandona ou não dá o suporte afetivo necessário, sendo esse um forte fator que prejudica a qualidade de vida da adolescente mãe, principalmente, no que se refere à saúde emocional.

Além da família e do cônjuge, a adolescente grávida também pode vir a buscar apoio com os seus contatos de amizade, todavia muitas sofrem com a discriminação dos amigos e da sociedade. As percepções do preconceito se traduzem por meio de sentimentos de medo, de raiva, de depressão e de vergonha afetando diretamente a sua saúde (MARANHÃO et al., 2018). Isso afeta também o desejo de dar continuidade ao processo de escolarização, já que a adolescente pode se sentir excluída pelas demais estudantes.

A estudante que foi entrevistada destacou alterações significativas em sua rotina, como as poucas horas de sono e, também, a dificuldade de gerir seu tempo com qualidade:

[...] porque assim, ela pra tudo vai depender de mim né! Eu tenho que estudar, trabalhar, esse processo todinho... eu era acostumada, eu saia e voltava a hora que eu queria, agora eu não posso mais. Não posso mais sair pra canto nenhum assim de passar muito tempo, porque agora tem ela (Sophia, 16 anos)

Há uma restrição da liberdade de circulação em decorrência da dependência do bebê, questão essa que pode ser amenizada, conforme se estabeleça um ritmo na relação mãe-bebê (aprendizagem de maternidade) ou agravado em meio a uma rede de apoio que use a gravidez/maternidade (considerada precoce) como método contraceptivo (para novas gravidezes) e punitivo, dificultando todos os processos de adaptação a esse momento complexo, que é a gravidez/ maternidade na adolescência. Não são poucos os relatos de adolescentes gestantes sobre a vivência de mal-estar, de vergonha, de desestímulo e de depressão durante a gravidez, no parto e pós-parto. Estudos como o de Brandão (2014) já vêm se dedicando à denúncia da violência obstétrica, que se agudiza quando a parturiente é adolescente. "Na hora de 
fazer não chorou" é uma das violências mais escutadas pelas adolescentes mães, o que tem repercussão significativa em toda a sua trajetória sexual e reprodutiva, afirmação essa que se faz em conexão com a prevalência do paradigma da culpabilização da adolescente e não em sintonia com o paradigma da responsabilização do Estado, embora o Brasil seja signatário de convenções internacionais de direitos sexuais e reprodutivos.

Apesar de todas essas violações e dificuldades, a adolescente que foi entrevistada positivou a maternidade nos seguintes termos: "Uma experiência boa né! Porque eu tô vendo aquela coisinha dependendo de mim [...] Pra tudo ela vai depender de mim [...] Penso em terminar e fazer faculdade de veterinária" (Sophia, 16 anos). A responsabilidade com a criança fortalece o desejo da adolescente em se manter em processo de escolarização, vislumbrando a partir deste lugar (a escola) a construção de uma oportunidade melhor de vida para si e para sua prole. Esse significado da gravidez/maternidade na adolescência produz uma contra hegemonia com relação às leituras que restringem os sentidos deste evento às perdas como a evasão, o que se observa em outros estudos é que o desestímulo com relação à escolarização antecede a gravidez/ maternidade, esta pode inclusive reconectar a adolescente com um projeto de escolarização, desde que a rede de apoio esteja comprometida a sustentar tal projeto (MENEZES et al., 2012; SOUSA et al., 2018).

É ressaltado por Sousa et al. (2018), também, que para as adolescentes, que não estão na escola, esse é um fator de risco para uma gravidez não planejada e para a aquisição de ISTs, visto que a escola pode e deve funcionar como uma rede de proteção fornecendo informações e apoio as/os estudantes.

Para o gestor entrevistado, o evento maternidade na adolescência já não seria mais algo novo, pois ele relata a frequência de adolescentes que engravidaram e estudam ou estudaram na escola em que o mesmo trabalha. Questionado sobre o conhecimento de alunas adolescentes mães na escola que administra, o mesmo respondeu: "Tenho várias, várias estudantes mães aqui, que passaram por mim em outros anos e as que ainda estão aqui, agora em séries finais, tá entendendo? Perto de sair da escola" (Gestor Cristiano, 53 anos). O trecho do relato explicitado acima corrobora com pesquisas realizadas em nosso país, que evidenciam o aumento de adolescentes grávidas, estando estas ainda em processo de escolarização (PONCIANO et al., 2019).

A naturalidade com que o gestor trata o evento maternidade na adolescência esbarra com a responsabilidade mensurada por ele para uma adolescente em processo de escolarização:

[...] Se você não souber lidar com esta questão, ela não vai ser favorável, mas se você souber lidar, está com a cabeça no lugar, você sabe o que você fez e que essa responsabilidade você não vai deixar nas mãos de outras pessoas, mas você vai assumir a tua responsabilidade, o teu papel de estudante, o teu papel de profissional e o teu papel de mãe (Cristiano, 53 anos).
É irônico observar a plena atribuição de responsabilidades advindas com a gravidez/maternidade da adolescente (estudante, profissional, mãe), e a ausência da menção a um processo de constituição de um sujeito livre, autônomo e responsável, capaz de fazer suas escolhas sexuais e reprodutivas, porque a ele/ela foram disponibilizados os meios necessários de informação e os insumos para prevenção e proteção de uma gravidez indesejada e/ou não planejada e de IST/HIV (preservativos, pílulas anticoncepcionais, entre outros métodos, oportunidades para um conhecimento qualificado sobre o próprio corpo). Aciona-se aqui a noção de planejamento reprodutivo como projeto de vida e não como medida a operar a partir da vivência de uma gravidez (o que comumente ocorre nos Postos de Saúde e recebe o nome de planejamento familiar).

Questiona-se esse conjunto de responsabilidades idealizadas pelo gestor em meio à omissão histórica das instituições sociais com relação à garantia de direitos sexuais e direitos reprodutivos ao logo do ciclo biográfico. Tornase essencial para um efetivo retorno às atividades diárias da adolescente mãe uma rede de apoio social ampla, entendendo esta como um reforço às estratégias de enfrentamento do indivíduo diante das situações desafiadoras de vida. Sem esse apoio, orientação e acompanhamento de instituições específicas como a família, a rede de saúde, a escola, a comunidade, dificilmente as mulheres têm oportunidade de acessar e garantir seus direitos reprodutivos e direitos sociais, entre esses o de Educação. O que pode gerar consequências de diversas ordens, sem escolaridade é muito difícil o ingresso no mercado de trabalho, e isso muitas vezes faz com que o ciclo das desigualdades sociais seja reproduzido (RODRIGUES; SILVA; GOMES, 2019).

Sobre a questão da gravidez na adolescência e o recorte de classe social, Menezes et al (2012) fazem uma reflexão de que existe uma dificuldade social generalizada de abordagem qualificada dos temas sexo/sexualidade/direitos sexuais e direitos reprodutivos com crianças e adolescentes. As repercussões de uma gravidez na adolescência para as camadas economicamente privilegiadas não comprometem, de imediato, a continuidade no processo de escolarização. Diferentemente das adolescentes pobres, as de classe média e alta comumente contam com uma rede de apoio mais articulada e que consegue sustentar seus projetos de vida.

Esse quadro torna visível a necessidade de elaboração de novas políticas públicas (em consonância com os direitos reprodutivos), que incentive a permanência e/ou retorno das mães adolescentes à escola, garantindo a inserção social dessas e evitando o círculo da pobreza que acomete parcela significativa das mulheres brasileiras e se apresenta também como fenômeno intergeracional (PADILHA, 2011; RODRIGUES; SILVA; GOMES, 2019).

A escola é uma Instituição que tem meios para trabalhar novas formas de pensar sobre sexualidade. Entretanto, o reconhecimento e abertura dos docentes para o trato 
da questão representa uma exceção, pois entre muitos é recorrente o discurso de que cabe à família, ao sistema de saúde, e não é responsabilidade docente discutir questões de sexualidade, que vão além de uma abordagem biológica, mas compreendendo os cuidados com o corpo, o prazer, a proteção contra a gravidez não planejada, as IST, as violências sexuais, as relações de gênero, a diversidade sexual, entre outras questões (ADRIÃO et al., 2017).

Tanto a coordenadora quanto o professor da Instituição Escolar pesquisada apresentaram nas entrevistas um discurso preventivo em relação à maternidade na adolescência, informando que a escola está discutindo sobre reprodução, mas conforme já referido isso só acontece nas aulas de Biologia. Destacaram a precocidade da gravidez na adolescência - “[...] aí ela ficou grávida, e isso chegou muito cedo" (Coordenadora Jéssica, 53 anos) - embora admitam que a maternidade trouxe mudanças positivas para a estudante que tem demonstrado mais responsabilidade e interesse nas atividades escolares, e apresentado o que denominam de mais maturidade:

Eu acho que ela melhorou bastante, não sei se ela acordou para vida, [...] Eu acho que ela amadureceu, vendo a necessidade do estudo na vida dela, ela precisa agora porque ela não tá mais sozinha, ela precisa guiar alguém [...] a postura dela hoje é outra. (Professor Heleno, 47 anos).

Pode-se destacar da fala da estudante e dos profissionais de educação uma produção discursiva contra hegemônica, que reconhece aspectos positivos da gravidez na adolescência, embora em ambos os discursos falte o devido dimensionamento do campo dos direitos sexuais e dos direitos reprodutivos e dos riscos que essa falta de leitura pode representar em curto e médio prazo para manutenção da adolescente em processo de escolarização, apesar e a despeito do seu desejo. Os campos da sexualidade e da reprodução precisam ser considerados em articulação com o campo dos direitos sociais, entendendo inclusive os impactos da dupla reprodução (sexual e social) na vida das mulheres. No próximo tópico se discutirá sobre os desafios da articulação entre direitos sexuais, direitos reprodutivos e direitos sociais.

\subsection{Havia uma lacuna no meio do caminho: dificuldades de acesso aos direitos sexuais, reprodutivos e sociais}

De acordo com Carvalho et al. (2012), a sexualidade é tomada como risco (IST, violência, gravidez) e não como direito para os/as adolescentes, porque não se investe em traçar a diferença entre os campos sexo/sexualidade e direitos sexuais. O sexo estaria atrelado à concepção de diferença sexual ancorada na biologia dos corpos, mas com entendimento discursivo e pautado em uma gramática cultural. A sexualidade, por sua vez, é um dispositivo histórico que recorre a técnicas móveis, que atuam produzindo sensações corporais, qualificando prazeres, intensificando o corpo em determinada direção. Os Direitos Sexuais envolvem um campo de articulação da sexualidade com os direitos humanos, que envolve liberdade, autonomia, integridade, segurança do corpo sexual, privacidade, prazer, expressão, escolhas reprodutivas livres e responsáveis, informação. No limite, esse campo de direitos demanda por uma vida sem violência e exploração sexual.

Os Direitos Reprodutivos são a garantia de meios que promovam a liberdade de escolha reprodutiva, reforçando o exercício mais amplo da cidadania, na conquista de garantias legais e na participação nas decisões públicas. Assim, compreende-se que o respeito a tais direitos e, principalmente, o aprendizado desses direitos não está restrito à vivência adulta da sexualidade (ADRIÃO et al., 2017). A partir desta compreensão são analisados os significados apresentados pela/os participantes do presente estudo sobre esse campo de direitos em articulação.

Percebe-se no discurso da adolescente mãe, lacunas no acesso às informações necessárias para suas vivências sexuais com segurança, prazer e proteção. A mesma ressaltou a falta da orientação necessária para o cuidado com o corpo, o uso de contraceptivos e a ausência de exames ginecológicos periódicos, mesmo após ter iniciado sua vida sexual ativa. Questionada sobre a realização de exames preventivos: "Não, nunca tinha feito, só durante a gestação" (Sophia, 16 anos). Segundo Quadros et al. (2012), a sexualidade na adolescência só ganha visibilidade com a gravidez, isso porque algumas adolescentes vivenciam constrangimentos quando acessam o Posto de Saúde, tanto os/as atendentes quanto os/as usuários/ as exercem vigilância sobre a sexualidade delas e passam a ficar "mal faladas" por procurarem um ginecologista, já que ir a esse profissional é indício de perda da virgindade. Em pesquisa realizada por Adrião et al. (2012), as jovens informaram pelo menos três estratégias para acessar exames preventivos, deslocam-se para Unidades de Saúde em outras localidades (distantes de seus bairros), usam a identidade de uma amiga que já é mãe ou entram para o atendimento com a amiga e informam na consulta que o atendimento é para ela.

Observa-se também em pesquisas realizadas com adolescentes que, embora haja uma preocupação dos pais em relação ao início da vida sexual de seus filhos, eles/elas se sentem despreparados para dialogar, o que leva os/as adolescentes a buscarem informações nem sempre seguras para as vivências da sexualidade.

Ainda, em relação ao campo dos direitos reprodutivos, a adolescente entrevistada parece compreender a necessidade da garantia de um acompanhamento médico durante o período de gestação. Ela realizou durante todo o período gestacional o seu pré-natal na rede pública de saúde do Estado, e como está previsto na Lei Federal $n^{\circ}$ 6.202/75 teve, em seu poder, após o nascimento da sua filha, a declaração de ausência física de 120 dias da escola, garantindo assim sua licença maternidade.

Através dos relatos do gestor, identifica-se um posicionamento afeitoà garantia da permanência da adolescente na escola em seu processo de gestação/maternidade. Contudo, o mesmo afirma não conhecer profundamente o que está 
descrito como direitos reprodutivos, quando questionado sobre a permanência da aluna adolescente mãe na escola:

Damos o direito, damos a oportunidade dela, conforme as instruções, conforme a lei, tá entendendo? Porque a própria lei flexibiliza, tá entendendo? Para a estudante esse direito. [...] Não conheço bem a fundo esses direitos permanentes da gestação da mulher, mas dentro dos direitos dela, do papel de estudante e de ser mãe, enquanto dever nosso [...]. Ela tem os seus direitos [...]. (Gestor Cristiano, 53 anos).

Padilha (2011) ressalta que a compreensão das escolas acerca dos Direitos Reprodutivos ainda se orienta por um discurso de prevenção, e defendem a ideia de que uma gravidez na adolescência sempre será algo indesejado, fora do padrão. A discussão no campo dos direitos é bem complexa e isso se agudiza no caso da adolescente mãe que, por um lado, tem no mesmo documento (ECA) enunciados com vistas ao seu direito como adolescente e ao direito de sua prole como criança. Pelo princípio da proteção integral (artigo 227 da constituição e $4^{\circ}$. Artigo do ECA) à criança e ao adolescente se deve garantir a efetivação dos direitos fundamentais (vida, saúde, alimentação, educação, lazer, profissionalização, cultura, dignidade, respeito, liberdade, convivência familiar e comunitária). A igualdade de condições de acesso e permanência na escola está previsto no artigo 206 da Constituição Federal, artigo 53 do ECA e artigo $3^{\circ}$ da Lei de Diretrizes e Bases da Educação. Há que se garantir uma forma de controle externo da manutenção do educando no Ensino Fundamental, de modo a contribuir para que a própria escola não motive a exclusão.

Quando o Decreto Lei $\mathrm{n}^{\mathrm{o}} 1.044$ (21/10/1969) - a partir do qual se ampara a Lei Federal $n^{0} 6.202$ (17/04/1975) estabelece, em seu artigo segundo, que a compensação da ausência às aulas dar-se-á sob a forma de exercícios domiciliares, com acompanhamento da escola, sempre que compatíveis com o seu estado de saúde e as possibilidades do estabelecimento não fica designado nenhuma instância de controle externo às próprias práticas escolares com relação à garantia da permanência da adolescente mãe em processo de escolarização. Articulando esse quadro com o campo dos direitos reprodutivos e sociais, a ausência de assistência à adolescente e sua prole se expressa na falta de creches, entre outros furos na rede de proteção à infância e adolescência em nosso país.

O afrouxamento das políticas públicas de saúde, educação e assistência está em conexão com um campo de direitos declarados, mas não assegurados. No contexto educativo se tem uma explícita falta de compromisso com questões de gênero e sexualidade, o que se revela na ausência de políticas de formação continuada em direitos humanos, sexuais e reprodutivos com ênfase no acesso, permanência e qualidade na educação. A abordagem desses direitos deve considerar questões de raça, de religião, de classe social e de orientação sexual, a fim de que seja garantido o pleno desenvolvimento de crianças e adolescentes.
A coordenadora entrevistada relatou que a escola vem cumprindo com o seu papel social, pois ela orienta sobre os cuidados que os/as alunos/as devem ter em relação às doenças sexualmente transmissíveis, a partir da promoção de palestras, chamando a família para conversar, orientando-as em relação as suas responsabilidades.

[...] a gente tem conversado, tem chegado perto, tem orientado, inclusive antes. Até as que não são mães a gente costuma orientar [...] durante o dia da mulher, por exemplo, a gente teve atividades voltadas para a orientação das mulheres [...] duas professoras de biologia trouxeram pra cá questões das doenças sexualmente transmissíveis, a questão do relacionamento com o outro, da maternidade, do câncer. (Coordenadora Jéssica, 53 anos).

A partir deste relato se pode observar uma prática comum dentro das escolas públicas do nosso país, a qual discute sobre sexualidade e reprodução dentro de um padrão dos problemas da prática sexual: a gravidez na adolescência e as IST, defendendo uma prática de prevenção e combate à gravidez e à proteção de doenças sexualmente transmissíveis, sem reflexões sobre prazer (PADILHA, 2011).

Não se está desconsiderando as consequências negativas das práticas sexuais sem a devida segurança e proteção, mas se pensa que esse padrão de entrada na discussão tem inviabilizado a abordagem da erotização e do desejo como vertentes fundamentais da prática sexual, inclusive, para que o uso dos métodos de proteção e de prevenção seja prazeroso.

Outra questão que chama a atenção é a ocorrência de um trabalho pontual, descontínuo, sem aprofundamento e em datas estratégicas. Ainda se destaca que é o discurso biológico que tem dominado a cena da produção da verdade sobre o saber da sexualidade. $\mathrm{Na}$ escola em tela, assim como na maioria, são os professores/as de Biologia e Ciências os responsáveis pela discussão. Há uma carência da ampliação do tema para outros saberes, em oposição às orientações diversas para um tratamento interdisciplinar e interseccional das questões de sexualidade. Outro ponto é condicionar a responsabilidade da discussão sobre esta temática aos pais e/ou responsáveis dos/as adolescentes, o que diverge de portarias de saúde e recomendações dos comitês de direitos das crianças e adolescentes. Esta é a posição do professor da adolescente, para quem a ausência de comunicação nas famílias contribui para a falta de informação segura dos/as filhos/as:

[...] eles me procuram, eu tenho uma facilidade porque eu tenho uma filha adolescente e eu sou bem natural, eu entendo das coisas, [...] mas do pai e da mãe em casa não tem orientação nenhuma. [...] a responsabilidade dos pais em casa não houve, não houve acompanhamento. (Professor Heleno, 47 anos).

Por fim, destaca-se do discurso da coordenadora o direcionamento das atividades de prevenção apenas com as adolescentes, reforçando a cultura sexista que atribuiu as mulheres a responsabilidade com a prevenção e a contracepção, sendo elas culpabilizadas quando algo foge ao seu controle. Importa lembrar que essa ordem sexista e 
machista incentiva que os homens tenham relações sexuais desde cedo e como prática fundamental ao estabelecimento de sua masculinidade, enquanto que para as mulheres "é tolhido o direito de falar sobre sexualidade em casa, na escola, na rua, com profissionais de saúde e até mesmo com seus companheiros" (QUADROS et al., 2012, p.154). É nessa condição de poucas oportunidades de aprendizagem qualificada e muitas cobranças quanto ao exercício de sua sexualidade que as mulheres vivenciam, desde muito cedo, o excesso de responsabilização e culpa, em detrimento ao seu devido empoderamento para a tomada de decisão sobre seus corpos.Compreende-se que o posicionamento dos profissionais participantes deste estudo acerca dos direitos reprodutivos aponta para uma orientação preventiva de cunho biológico, como a melhor forma de prevenir a gravidez na adolescência, ainda na tentativa de inibir a atividade sexual dos adolescentes em processo de escolarização.

Esses mesmos profissionais também alegaram conviver com a ausência de representantes responsáveis destes adolescentes, afirmaram não haver educação sexual e reprodutiva no âmbito familiar. Ainda é possível perceber a falta de conhecimento sobre os direitos reprodutivos, mas, ao mesmo tempo, esses profissionais trazem, em seus discursos, elementos desses direitos, como a necessidade da licença maternidade para a aluna adolescente mãe.

A reflexão sobre juventude, direitos sexuais e direitos reprodutivos e sociais solicita atenção ao contexto sociocultural e econômico, no qual os/as jovens estão inseridos/as, bem como ao conjunto de crenças, de valores, de interesses, de normas e de práticas sociais que circunscrevem suas existências na relação com instituições sociais e suas redes de convívio e apoio (ADRIÃO et al., 2017).

Encontra-se ainda no discurso da estudante adolescente mãe entrevistada, que as informações recebidas a respeito da sexualidade, métodos preventivos e reprodução em seu contexto social não foram recebidas na Instituição Educacional, rede pública de saúde e família, mas através de amigos/as e mídias de comunicação acessadas por ela, o que corrobora com o localizado em outros estudos (CRUZ et al., 2018).

\subsection{Presença da lei/ausência do acompanhamento domiciliar: desafios ao cumprimento da licença maternidade pela rede escolar}

Pode-se perceber que a estudante, em princípio, não vê a maternidade como uma impossibilidade de dar continuidade ao seu processo de escolarização. A adolescente afirma ter frequentado a escola durante toda a sua gestação, ausentandose apenas no período de nascimento de sua filha, como se pode conferir a seguir:

Eu continuei estudando. Ela nasceu de oito meses, então eu fiquei até oito meses. [...] eu não sentia dor, só um pouquinho no pé da barriga, porque o parto foi normal entendeu? Aí já tava com dilatação, só que eu tava andando pra lá e pra cá e não sabia. [...] eu tava frequentando a escola normal, e a menina já querendo sair. (Sophia, 16 anos).

Merece destaque que a estudante antecipou seu retorno à escola, embora afirme que lhe foi assegurado o direito de se ausentar fisicamente durante 120 dias, com a devida documentação que lhe foi entregue na rede de saúde (Atestado Médico). Causa estranhamento o não usufruto integral desse direito, pois a estudante só gozou de 30 dias, alegando que não queria ser prejudicada em seus estudos: “[...] eu ia perder muito assunto na escola, com um mês eu perdi, imagina 120 dias em casa, eu não ia saber nem pra onde ir... ia perder nota, perder tudo" (Sophia, 16 anos). A aluna teve seu retorno às aulas após um mês do nascimento da sua filha e, nesses dias longe da escola, não teve nenhum tipo de acompanhamento domiciliar da Instituição Escolar.

A gestão escolar reconhece o direito à licença, mas não desenvolveu nenhuma estratégia para que a adolescente pudesse usufruir de seu direito, produzindo assim um duplo agravo, à mãe e ao seu bebê. A licença à gestante é um direito de proteção à mulher, mas também se trata de um direito à criança usufruir da companhia de sua mãe, sendo este direito reconhecido pelo próprio Estatuto da Criança e do Adolescente desde o parto, uma vez que se obriga o Hospital a manter alojamento conjunto, possibilitando ao neonato a permanência junto à mãe (artigo 10, parágrafo $\mathrm{V}$, do ECA). Sabe-se ainda que a proteção à maternidade e à infância constitui direito social (conforme o artigo sexto da Constituição Federal) e, principalmente, para a adolescente mãe se trata de um período de aprendizagem com seu bebê.

Procedendo dessa forma a escola afirma que não se opõe à presença da adolescente grávida em seu contexto, mas não se implica em assegurar seu processo de escolarização. Este inclusive deve ser entendido como a garantia de acesso e permanência em uma escola de qualidade. Repete-se aqui uma realidade que já se havia percebido quando a adolescente grávida informou que os/as professores/as não passam avaliação dos conteúdos para ela em uma clara afirmação de que o seu processo de aprendizagem não merecia ser alvo de atenção. Esta realidade presente na escola pública pesquisada diz o quanto o direito a uma educação digna para todos e todas precisa ser radicalmente questionado. $\mathrm{O}$ que se produz é uma sutil exclusão que, mais uma vez, vai culpabilizar e responsabilizar a adolescente mãe pelo seu fracasso escolar.

A instituição pesquisada não se planejou para dar o devido suporte à estudante e alegou não ter quantitativo de pessoas suficiente para trabalhar e fazer corretamente o acompanhamento.

Porque a escola faz a parte que compete, mas elas precisam de muito mais e às vezes a escola também não tem suporte suficiente, porque a gente não tem equipe de psicólogo, pedagogo específico né, de psicopedagogo, pra chegar perto, pra fazer um acompanhamento sistemático, pra orientar de forma mais sistemática mesmo. Fazer um acompanhamento permanente da vida dessa adolescente enquanto mãe e aluna. (Coordenadora Jéssica, 53 anos). 
Rohr e Schwengber (2013) chamam a atenção para a necessidade de um trabalho de acompanhamento específico realizado pela equipe da Instituição Escolar, no oferecimento de oportunidades, como trabalhos a distância, entre outras iniciativas que mantenham o vínculo da estudante e a qualidade da aprendizagem.

Quando os serviços de saúde e educação deixam de advogar por uma política de atendimento dirigida aos/as adolescentes, reforçam a posição dominante de que as pessoas em desenvolvimento não têm direito sobre o exercício de sua própria sexualidade. Isso faz com que resida um problema na sociedade, porque essa posição dominante não colabora no aprofundamento de um debate mais específico sobre essa questão, que inclua debates como diversidade sexual, relações de gênero, entre outros, e contribui para inibir uma atitude de autonomia dos/as adolescentes em relação a sua saúde sexual e reprodutiva (BRABO; SILVA; MACIEL, 2020).

Em meio a tantos agravos ao campo dos direitos se sabe que a estudante que foi entrevistada é uma exceção em meio a uma estatística que indica que muitas adolescentes mães, sobretudo, as que fazem parte de uma classe social desfavorecida economicamente, não conseguem retornar à escola, por não terem com quem deixar a criança, por desmotivação para retornar os estudos, por não se sentirem acolhidas e, em alguns casos, por vergonha (PADILHA, 2011; ROHR; SCHWENGBER, 2013; RODRIGUES; SILVA; GOMES, 2019).

\section{Conclusão}

No presente estudo se refletiu sobre as dificuldades enfrentadas por adolescentes em processo de escolarização concomitantemente com a experiência da maternidade. Identificam-se as lacunas existentes em uma Instituição Escolar quando essa foi investigada sobre a garantia de direitos sexuais, reprodutivos e sociais para uma adolescente mãe.

Considera-se importante uma discussão, no âmbito escolar, que promova a abertura do tratamento dos temas relacionados aos direitos sexuais e direitos reprodutivos em articulação com os direitos sociais de adolescentes, e que esta não seja apenas na forma de uma orientação preventiva de cunho biológico, mas que proponha a orientação segura e saudável a esses/as, a fim de que possam alcançar o bem-estar sexual e sua autonomia sexual e reprodutiva.

Percebem-se as dificuldades vivenciadas pela estudante no processo de maternidade, como as mudanças na sua rotina diária e a falta de preparo para os cuidados com o bebê. Viu-se também que o evento da maternidade proporcionou que a estudante pudesse ressignificar positivamente sua escolarização como um projeto de vida conjunto para contribuir na sua qualidade de vida e da prole.

Destacam-se as lacunas no conhecimento dos profissionais de educação sobre os direitos reprodutivos, mais especificamente, a vinculação destes com a Lei $n^{\circ}$
6.202/75, que assegura as alunas adolescentes mães o direito de afastamento de suas atividades escolares, a partir do oitavo mês de gestação, podendo se estender por até 120 dias.

Em pesquisas bibliográficas se pode identificar que muitos trabalhos não abordam a referida Lei na perspectiva dos Direitos reprodutivos e sociais. Nesse sentido, acreditase ser importante o desenvolvimento de leituras críticas que contribuam para divulgação da Lei também em articulação com o Estatuto da Criança e do Adolescente que, por sua vez, precisa ser cobrado quanto a sua omissão de uma abordagem positiva dos direitos sexuais desde a infância.

$\mathrm{O}$ presente estudo buscou contribuir com trabalhos desenvolvidos em escolas públicas do nosso país, no que se refere à garantia dos direitos sexuais e reprodutivos para estudantes de todos os sexos e todos os gêneros. Faz-se necessário que o exercício responsável da sexualidade seja uma ação política de todas/os e não um objeto de cobrança e culpabilização para crianças, adolescentes e jovens que, sob a égide da perspectiva adultocêntrica, sejam considerados incapazes do ponto de vista de suas sexualidades e direitos. A onda conservadora e fundamentalista que assola nosso país desde pelo menos o ano de 2015 - com uma série de projetos de lei e Emenda à Constituição - ameaça a autonomia de escolas, universidades e docentes que tratam dos temas de gênero e sexualidade e pede resposta enérgica com vista à garantia de direitos e das gerações que sucedem. Que sejam fortes e corajosos nesse enfrentamento.

No dia 02 de fevereiro de 2020 foi lançada uma política para a prevenção da gravidez na adolescência pelo Governo Federal, a proposta é que seja utilizada como método preventivo a prática da abstinência sexual, não se pode dizer ao certo o que isso irá ocasionar, mas pelos estudos que já existem, acredita-se que essa é uma medida que busca controlar os corpos, as vidas, e desconsidera que o sexo não é uma prática apenas para a reprodução, mas também para o prazer. O fortalecimento das práticas de dupla proteção junto às informações de qualidade poderão ser um eficiente aliado à prevenção de gravidezes indesejadas, IST, e de aprendizados para o cuidado com o corpo e a saúde de modo geral.

\section{Referências}

ADRIÃO, K. et al. Significados e práticas relacionadas à gravidez na adolescência em diferentes redes de convívio e apoio: um estudo comparativo entre as mesorregiões da região metropolitana do Recife e do Sertão (PE). Relatório de pesquisa: FACEPE/CNPQ, 2012.

ADRIÃO, K. et al. Circuitos integrados? Intersecções de gênero, sexualidade e geração nas vivências afetivo-sexuais de um jovem e sua rede de convívio no nordeste do Brasil. In: OLIVEIRA, J.M.; AMÂNCIO, L. (Org.). Géneros e sexualidades: interseções e tangentes. Maiadouro: Porto, 2017. p.175-192.

BRABO, T.S.A.M.; SILVA, M.E.F.; MACIEL, T.S. Gênero, sexualidades e educação: cenário das políticas educacionais sobre os direitos sexuais e reprodutivos de jovens e adolescentes. Práxis Educativa, v.15, e2013397, 2020. doi: https://doi.org/10.5212/ PraxEduc.v.15.13397.003 
BRANDÃO, P.S. A violência obstétrica à adolescente é uma realidade. In: REDE UNIDA. ENCONTRO REGIONAL CENTRO-OESTE, 2014. Anais... Resumo. Disponível em: http://conferencia2016.redeunida.org.br/ocs/index.php/regionais/ centro-oeste/paper/view/219. Acesso em: 10 jun. 2019.

BRASIL. Secretaria de Educação Fundamental. Parâmetros Curriculares Nacionais: introdução aos parâmetros curriculares nacionais. Brasília: MEC; SEF, 1997.

CARVALHO, M.B.; MATSUMOTO, L.S. Gravidez na adolescência e a evasão escolar. Educação, 2009. Disponível em: $\quad<$ http://www.diaadiaeducacao.pr.gov.br/portals/pde/ arquivos/1868-8.pdf>. Acesso em: 30 dez. 2019.

CARVALHO, C.S. et al. Direitos sexuais de crianças e adolescentes: avanços e entraves. Psic. Clin., v.24, n.1, p.69-88, 2012.

CRUZ, L.Z. et al. Conhecimento dos adolescentes sobre contracepção e infecções sexualmente transmissíveis. Adolesc. Saúde, v.15, n.2, p.7-18. 2018.

MARANHÃO T.A. et al. Atitudes e Reações Familiares e Sociais diante da gravidez na adolescência. Enferm. UFPE On Line, v.12, n. 4, p.840-848, 2018.

MENEZES, J.A. et al. Gravidez e maternidade na adolescência e suas repercussões no processo de escolarização. Rev. Percursos, v.13, n.2, p.134-154, 2012.

MINAYO, M.C.S. O desafio da pesquisa social. In: DESLANDES, S.F.; GOMES, R.; MINAYO, M.C.S. (Org.). Pesquisa social: teoria, método e criatividade. Petrópolis: Vozes, 2009. p.9-29
MORAES. S.P.; VITALLE. M.S.S. Direitos Sexuais e reprodutivos na adolescência. Rev. Assoc. Med. Bras., v.58, n.1. p.48-52. 2012.

PADILHA, M.A.S. As representações sociais da evasão escolar para mães adolescentes: contribuição para a enfermagem. Pelotas: Universidade Federal de Pelotas, 2011.

PONCIANO, J.K. et al. A maternidade e a evasão escolar das jovens no ensino médio: considerações preliminares. Cad. Saúde Coletiva, v.26, n.2, 2018.

QUADROS, M.T. et al. Mulheres jovens, sexualidade e redes de convivência em uma comunidade rural de caruaru/PE: circuitos (des) integrados. Rev. Anthropológicas, v.23, n.1, p.137-159, 2012.

RODRIGUES, L.S.; SILVA, M.V.O.; GOMES, M.A.V. Gravidez na adolescência: suas implicações na adolescência, na família e na escola. Rev. Educ. Emancipação, v.12, n.2, 2019. doi: http:// dx.doi.org/10.18764/2358-4319.v12n2p228-252

ROHR. D.R.; SCHWENGBR. M.S.V. A escola e "as barrigas". Rev. Contexto Educ., v.28. n.90. p.183-206, 2013.

SOUSA, C.R.O. et al. Fatores preditores da evasão escolar entre adolescentes com experiência de gravidez. Cad. Saúde Colet., v.26, n.2, 2018. doi: http://dx.doi.org/10.1590/1414$462 \times 201800020461$

STEIN, K.S.C. Gravidez e maternidade no período escolar: vivências de jovens e professoras de escolas públicas de Guarujá e Santos. São Paulo: Universidade Federal de São Paulo, 2018. 